Bull. Mater. Sci., Vol. 6, No. 3, July 1984, pp. 491-501. (C) Printed in India.

\title{
Applications of scanning transmission electron microscope microanalysis in the study of materials
}

\begin{abstract}
GARY R PURDY
Department of Metallurgy and Materials Science, McMaster University, Hamilton, Ontario, Canada

Abstract. The dedicated STEM equipped with field emission electron source, affords opportunities for the acquisition of microchemical and microstructural data on a scale approaching the nanometer level. In this presentation, a number of applications of microchemical analysis and microdiffraction to engineering materials will be discussed, with major emphasis on high-strength low-alloy steels, steels for high formability in automotive applications, and aluminium alloys. Some advantages and limitations of the technique are noted, especially for application to analysis of electrochemically prepared thin foils, and to the analysis of extracted particles.
\end{abstract}

Keywords. STEM; microanalysis; dual phase steels; high strength and low alloy steels.

\section{Introduction}

In the two years since the joint McMaster-Toronto STEM facility was established, a number of experimental programmes have been undertaken, and a few brought to conclusion. This paper reviews selectively those examples of STEM microanalysis which have been most fruitful in establishing working, or "effective" limits on instrument performance, given a multi-user environment. In general, the problems have been chosen with a particular scientific or engineering objective in mind, rather than for optimum instrumental performance. Hence, they serve to demonstrate the potential of the STEM for providing useful microchemical information to complement that derived from more conventional studies.

\section{The instrument}

The instrument is a "dedicated" vacuum generator HB-5 STEM, with field emission electron source, energy-dispersive $x$-ray, and electron energy loss spectrographic capabilities. In addition, it is possible to record diffraction patterns using well-focussed beams of varying convergence. The overall performance of the instrument is essentially as specified by the supplier, but certain development programmes have been undertaken to improve the energy loss spectrometer performance, and the microdiffraction recording capability.

\section{Studies of thin-foil specimens}

\subsection{Dual phase steels}

The problem of austenite growth in the intercritical annealing of dual phase steels has been treated analytically by Speich et al (1981) and Wycliffe et al (1981). The results of 
the two treatments are at variance, largely because of the type of local equilibrium that is assumed to hold at the austenite-ferrite interface during growth. Speich et al (1981) assume a partial or paraequilibrium (Hillert 1960; Gilmour et al 1972) for initial growth, followed by a transition to particular interfacial tie-line representative of global equilibrium within the specimen. In contrast, the analysis of Wycliffe et al (1981) presumes that a full local equilibrium is attained during initial growth, and that a series of tie-lines representing successive local equilibria are determined as part of the solution of the diffusion equations (figure 1).

The test of these hypotheses requires that high-resolution microanalyses be performed on well-characterized specimens of previously homogenized steels, quenched from isothermal treatments in the intercritical temperature range.

Two techniques were adopted to study the manganese profiles in austenite and ferrite after intercritical annealing: The first was conventional microprobe analysis, using deconvolution techniques (Gilmour et al 1972) to enhance the spatial resolution to the point where it was limited by statistical and instrumental factors. Figure 2 shows a convolution of the predicted Mn profile through an austenite (martensite) particle with the experimentally determined microprobe intensity distribution function. Note that this specimen was annealed for $50 \mathrm{hr}$ at $1023 \mathrm{~K}$. While the agreement is satisfactory, it is seen that this represents an upper limit to the capability of the microprobe analyser, and does not relate decisively to the more interesting short-time intercritical treatments.

The same specimen was sectioned and examined in the STEM (figure 3). It is clear that the increased spatial resolution of the STEM allowed a more nearly complete and direct determination of the maximum manganese concentration at the austenite-ferrite interface, in spite of the somewhat greater statistical error (discussed below). For shorter times, e.g. $100 \mathrm{sec}$ the STEM allowed the detection of a manganese-enriched rim in the austenite, as shown in figure 4. These results for short times, and others like them
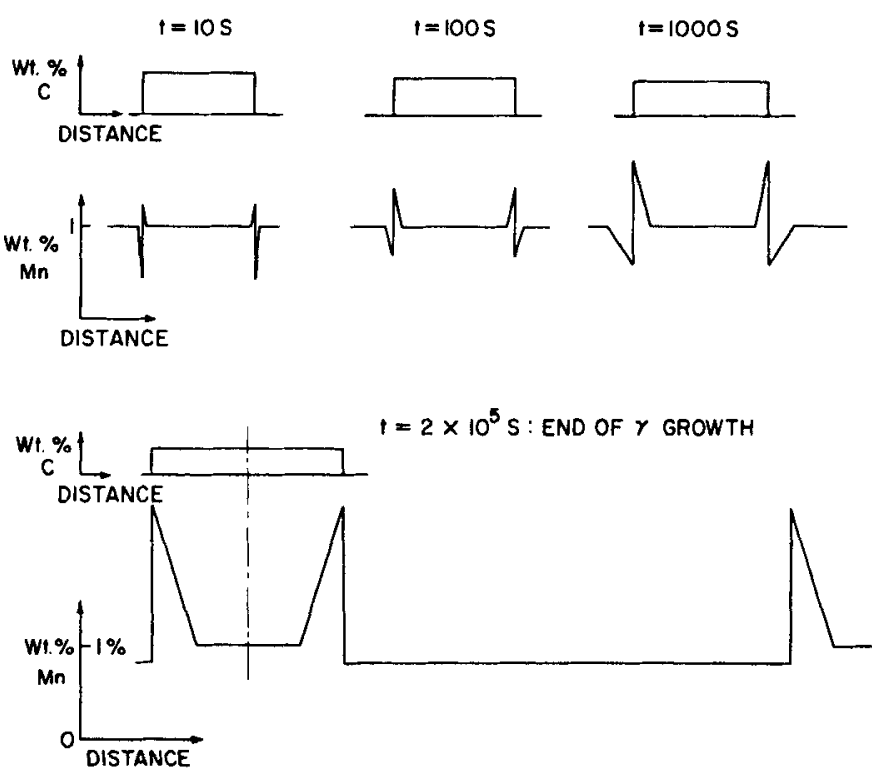

Figure 1. Computed carbon ( $\mathrm{C} 1$ ) and manganese $(\mathrm{C} 2)$ profiles for a $1 \% \mathrm{Mn}$ dual phase steel annealed for $50 \mathrm{hr}$ at $1023 \mathrm{~K}$, assuming a spherical austenite particle initially $1 \mu \mathrm{m}$ in radius. 


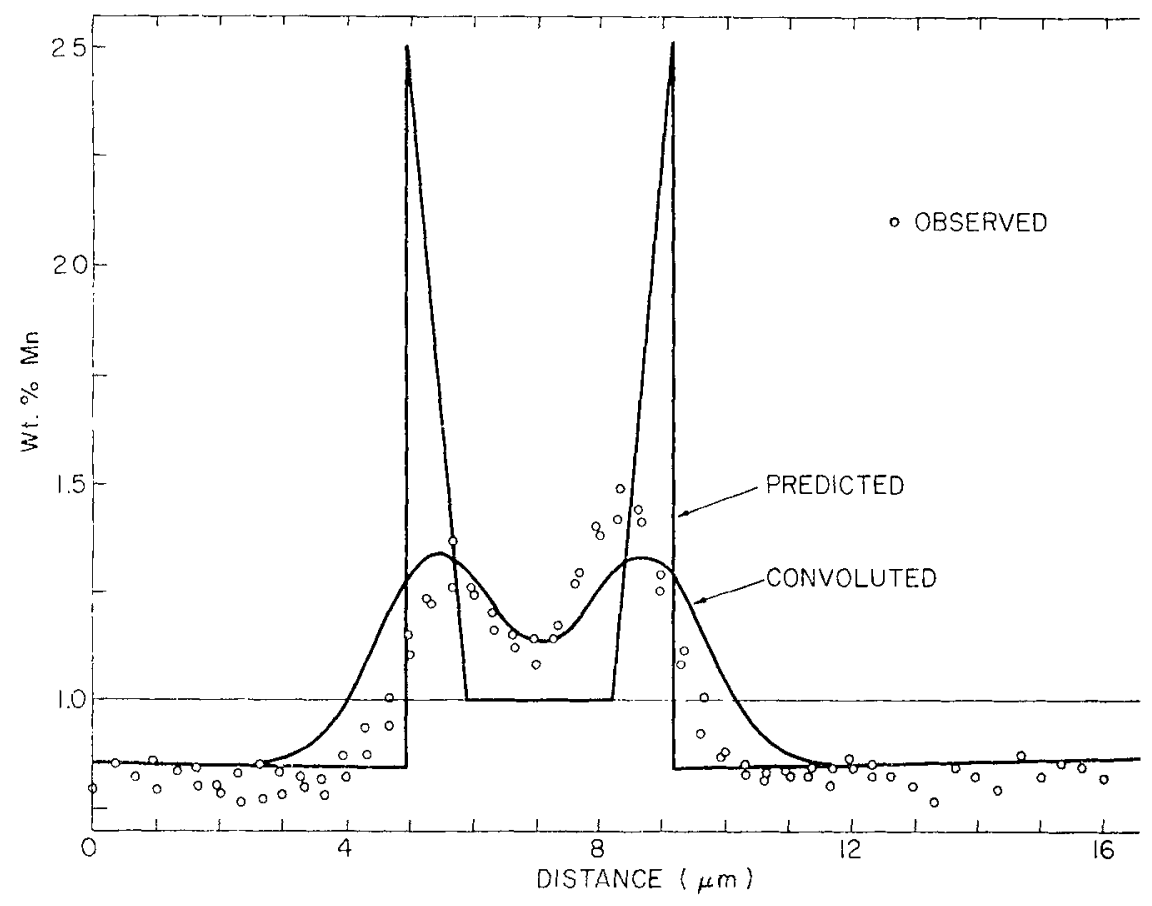

Figure 2. A predicted concentration profile is compared with an expected microprobe trace and compared with experimental points for an Fe-0.08\% C-1\% Mn alloy annealed for $50 \mathrm{hr}$ at $1023 \mathrm{~K}$

lend credence to the full local equilibrium analysis as applied to intercritical annealing times typical of continuous processing routes. The longer time heat treatments are relevant to batch processing.

The sources of error in these analyses are of interest (Wycliffe 1981). It was determined that $\mathrm{x}$-ray absorption in the specimen should have negligible effect on characteristic or background intensities, for the range of foil thickness and take-off angles employed. The major problems in obtaining precise information about the distribution of manganese in these rather dilute alloys are therefore statistical in origin, and involve precision in the measurement of both peak and background intensities; a schematic $x$-ray spectrum is shown in figure 5 . The background intensity was estimated by extrapolating normalized integrated counts in the windows $\mathrm{W} 1, \mathrm{~W} 2, \mathrm{~W} 3$, and $\mathrm{W} 4$ (as a linear regression in $1 / E$ ) to the manganese window. In treating the data in this way, Wycliffe encountered a systematic error, which is tentatively attributed to a low-energy (non-gaussian) contribution from the adjacent iron line. This detector characteristic was not suspected previously.

The austenite particles are approximately spherical; thus sectioning effects can distort the concentration profiles even when statistical factors are fully optimised. In an extreme case, a section through the manganese-enriched rim of an austenite particle would suggest uniform enrichment. In the more usual case, the interface is inclined to the foil and the net effect is a reduction in amplitude and a broadening in space of the interfacial concentration variation. 


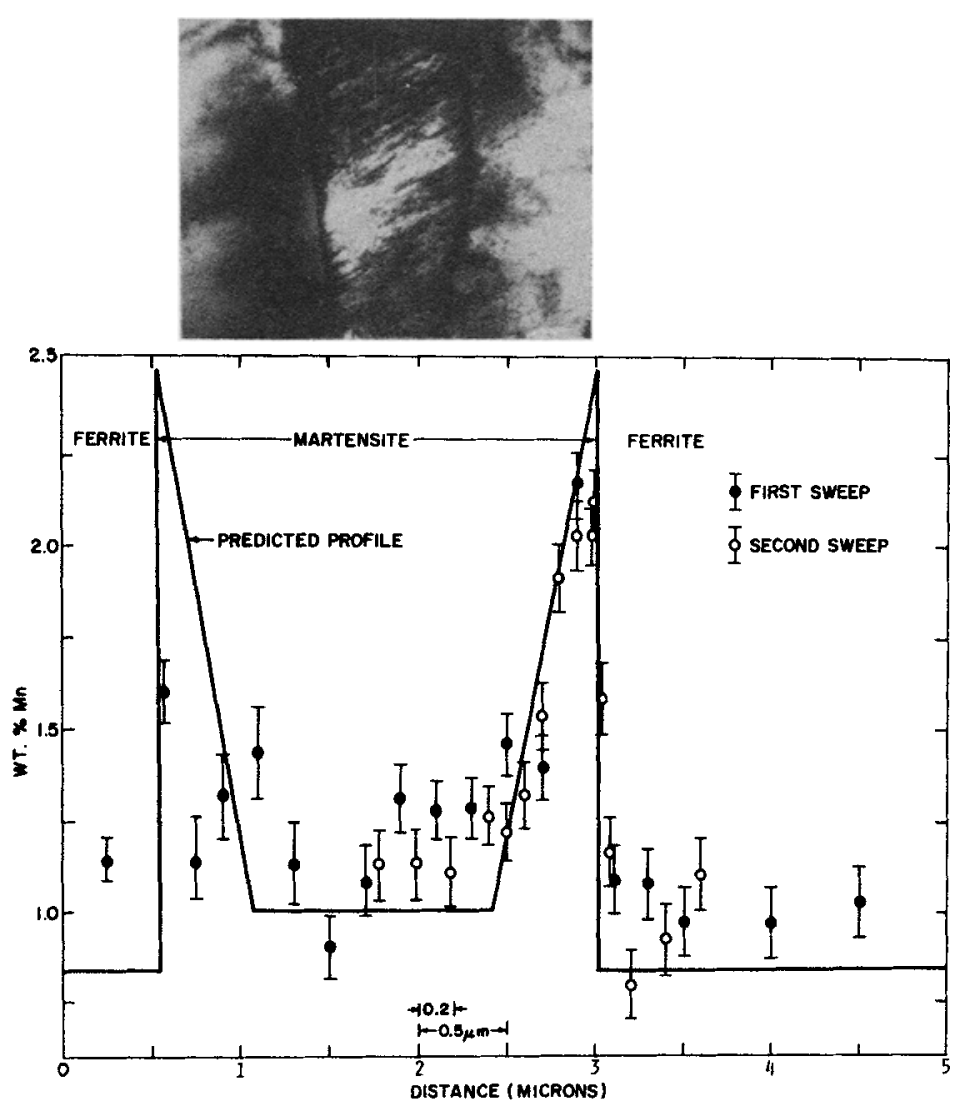

Figure 3. STEM microanalytical results are compared with a predicted concentration profile. $\mathrm{Fe}-0.08 \% \mathrm{C}-1 \% \mathrm{Mn}, 50 \mathrm{hr}$ at $1023 \mathrm{~K}$. The greater thickness at the left hand side of the particle caused broadening of the apparent concentration peak.

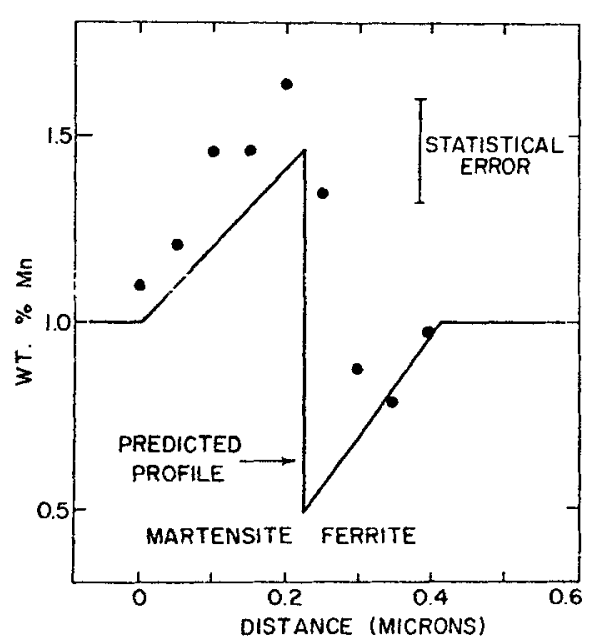

Figure 4. STEM analysis for the interfacial concentration profile from a specimen annealed for $100 \mathrm{sec}$ at $1023 \mathrm{~K}$. 


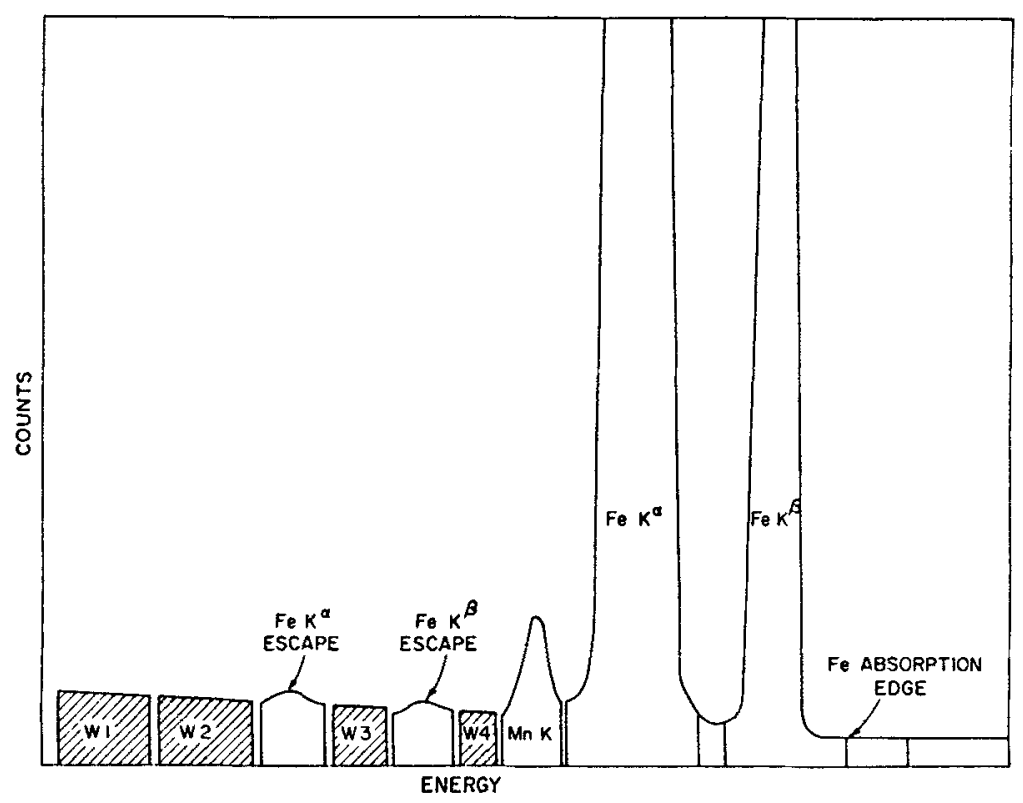

Figure 5. Schematic of an $x$-ray spectrum. The shaded regions were used in a linear regression of the normalized $\mathrm{Mn}$ background on $1 / E$.

It is expected that beam spreading (Goldstein 1979) is the other chief source of loss of spatial resolution in these iron-base alloys; for a typical foil thickness of $100 \mathrm{~nm}$, the estimated beam-spreading contribution to source size is $20 \mathrm{~nm}$ compared with the original probe diameter of approximately $1 \mathrm{~nm}$. Deconvolution techniques can be applied to deal with this problem for some systems. They are not, however, justified for the present case.

Thus the technique of STEM $\mathrm{x}$-ray microanalysis has proven valuable in the study of dual-phase steels. However, it should be noted that spectrometer and specimen limitations restrict the detectability of alloying element variations of lesser amplitude. A search for transformation-induced moybdenum segregation in a series of $\mathrm{Fe}-\mathrm{C}-\mathrm{Mo}$ alloys was less conclusive (Brown et al unpublished) mainly because the expected amplitude of segregation is at the margin of detectability.

\section{Studies of aluminium alloys}

The discontinuous-precipitation reaction in $\mathrm{Al}-\mathrm{Zn}$ alloys is of fundamental as well as practical interest. Here a departure from local equilibrium is expected and necessary, and the solute $(\mathrm{Zn})$ distribution at the transformation front is of interest from several points of view. A knowledge of the solute profile across the Al-rich regions is capable of analysis to yield the diffusion coefficient in the moving interface and a measure of the residual supersaturation left behind the moving front. In addition, the value of the composition in the depleted $\alpha$ immediately adjacent to the $\mathrm{Zn}$-rich phase is required for a full analytical description of the process. Solorzano-Naranjo and Purdy (unpublished) have studied the composition profiles left behind the front, using 


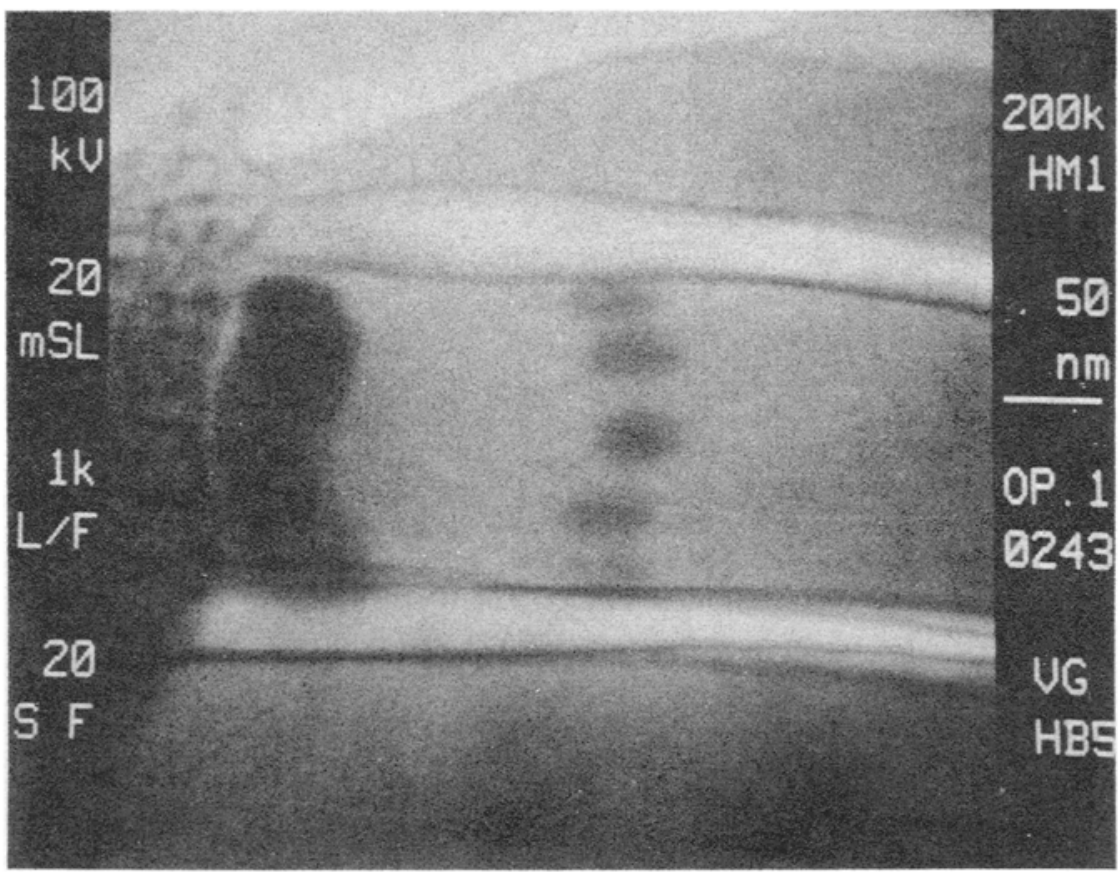

Figure 6. A STEM micrograph of the transformation front in an Al-28 at $\% \mathrm{Zn}$ alloy, $10 \mathrm{~min}$ at $433 \mathrm{~K}$. Scans across the depleted matrix are indicated by contamination traces.

electrolytically prepared foils from which the zinc-rich phase has been dissolved (figure 6). The results obtained to date suggest that these profiles are consistently and remarkably flat, allowing the assignment of a lower limit only to the interfacial diffusion coefficient.

A second example of the application of the STEM to aluminium-base system is that of $\theta^{\prime}$ precipitation in $\mathrm{Al}-4 \% \mathrm{Cu}$. Here, it is possible to obtain microdiffraction information from individual $\theta^{\prime}$ plates (on edge) and to image individual growth ledges (figure 7). The solute field in the vicinity of the plates is accessible*, and it would be particularly interesting to map the copper distribution around an individual growth ledge. Current research (Perovic et al 1984) aims to compare the theory of ledge migration with experimental microchemistry.

\section{Studies of isolated or extracted particles}

The thin foil technique, although extremely useful in the study of gradients near interfaces, is limited in its application to the study of small particles, which are often obscured by matrix effects. Here, as an alternative, the study of extracted particles, supported on thin carbon (or other innocuous) substrates, has value.

The main example considered here, from the work of Houghton et al (unpublished)

*It is found that a brief treatment in an ion-thinning device is a useful precaution before examining electrochemically prepared Al-Cu foils. 


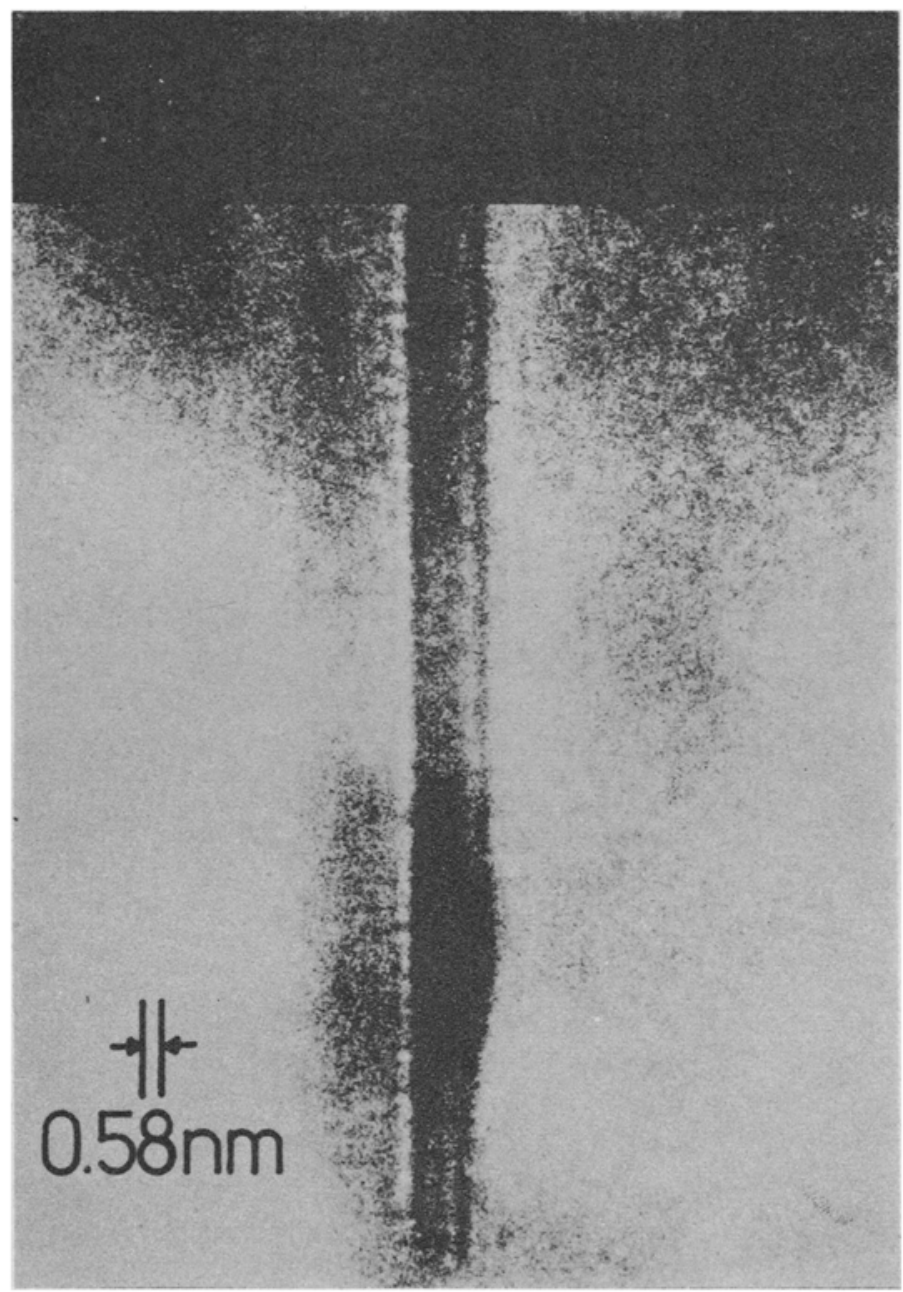

Figure 7. A $\theta^{\prime}$ plate, imaged edge-on, to show a growth ledge.

was particularly useful to study precipitation sequences in high-strength low-alloy steels, subject to complex thermomechanical processing. The steels studied contained approximately $0.065 \mathrm{C}, 2 \% \mathrm{Mn}, 0.3 \% \mathrm{Si}, 0.3 \% \mathrm{Mo}, 0.003 \% \mathrm{~S}, 0.005 \% \mathrm{Nb}$ and had varying titanium and nitrogen levels, from 0.011 to $0.039 \%$ and from 0.005 to $0.010 \%$ respectively (all concentration values in $\mathrm{wt} \%$ ). They were examined in the as-cast, reheated and control-rolled condition. In addition, several specimens were given thermal cycles designed to simulate the thermal history of the heat affected zone in a submerged arc welding process.

In conjunction with other metallographic techniques, the STEM proved most useful in identifying small carbonitride particles, and in establishing precipitation sequences. Figure 8 is a schematic histogram showing the size, shape and chemical composition of a typical precipitate distribution for a control-rolled alloy, along with probable formation temperatures. Figure 9 shows a STEM image, $x$-ray spectra, and micro- 


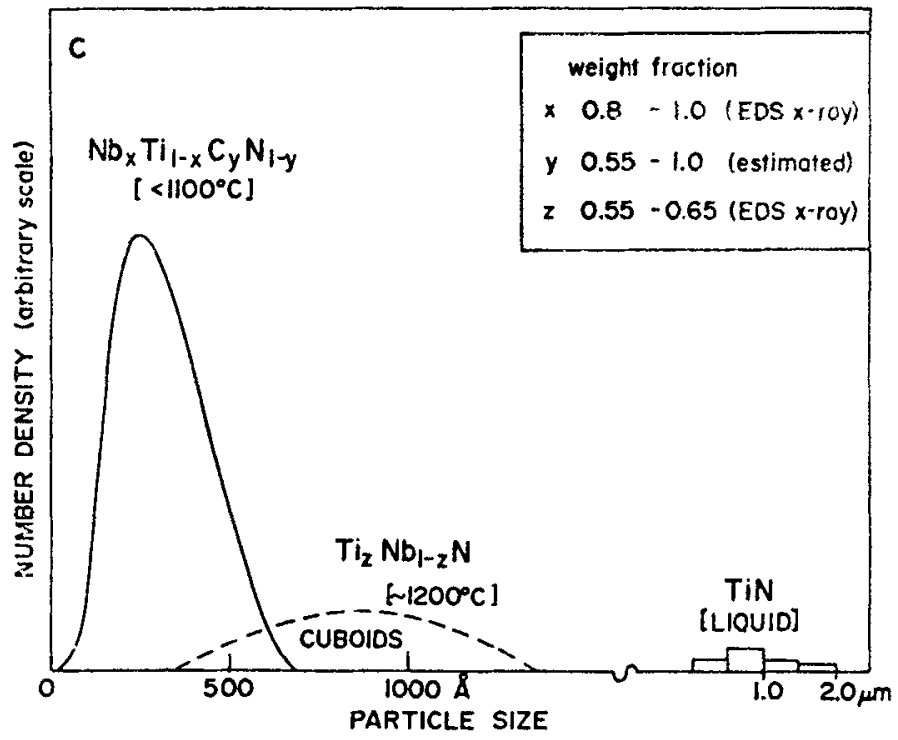

Figure 8. A schematic histogram showing the size, shape and chemical compositions of a typical precipitate distribution and probable formation temperatures.

diffraction patterns from a non-uniform particle, showing that epitaxial niobium-rich caps formed heterogeneously on the titanium-rich cubic central region of the particles.

By combining STEM-derived information with CTEM lattice parameter determinations (used to determine $C / N$ ratios) and the solubility-product data of Narita (1975), it was made possible to establish predictive, simplified models for the precipitation sequence. The stable precipitate in austenite responsible for grain boundary pinning was identified in this work as $\mathrm{Ti}_{x} \mathrm{Nb}_{1-x} \mathrm{~N}$, where $x$ is of order $0 \cdot 6$; precipitates developed in control-rolled microstructures are of two major species: High temperature $\mathrm{Ti}_{x} \mathrm{Nb}_{1-x} \mathrm{~N}$, formed during soaking; and carbonitrides of the general form $\mathrm{Nb}_{x} \mathrm{Ti}_{1-x}\left(\mathrm{C}_{y} \mathrm{~N}_{1-y}\right)$. The latter precipitates were frequently found to be inhomogeneous (figure 9).

A final example of the utility of the sTEM in the study of supported particles is in the study of the annealing behaviour of sputtered films (Lowden and Houghton (unpublished)). An unexpected result for $\mathrm{Cu}-\mathrm{Cr}$ films containing a few percent chromium was the development of large-faceted copper crystals, which grow out of the plane of the foil (figure 10). The STEM is used here both as a microanalytical tool and as a high-resolution scanning electron microscope to image the copper crystals and to demonstrate their three-dimensional faceted morphologies in a manner not possible in the transmission mode. The details of the growth of these crystals are not yet clear, but it appears that they are essentially the result of abnormal grain growth in an inherently fine-grained initial thin foil. The experimental details and theoretical analysis of this most interesting effect await fuller study.

\section{Conclusions}

Some examples of the application of STEM microanalysis to the study of materials have been reviewed. It is clear from the experience gained to date that the STEM offers the 

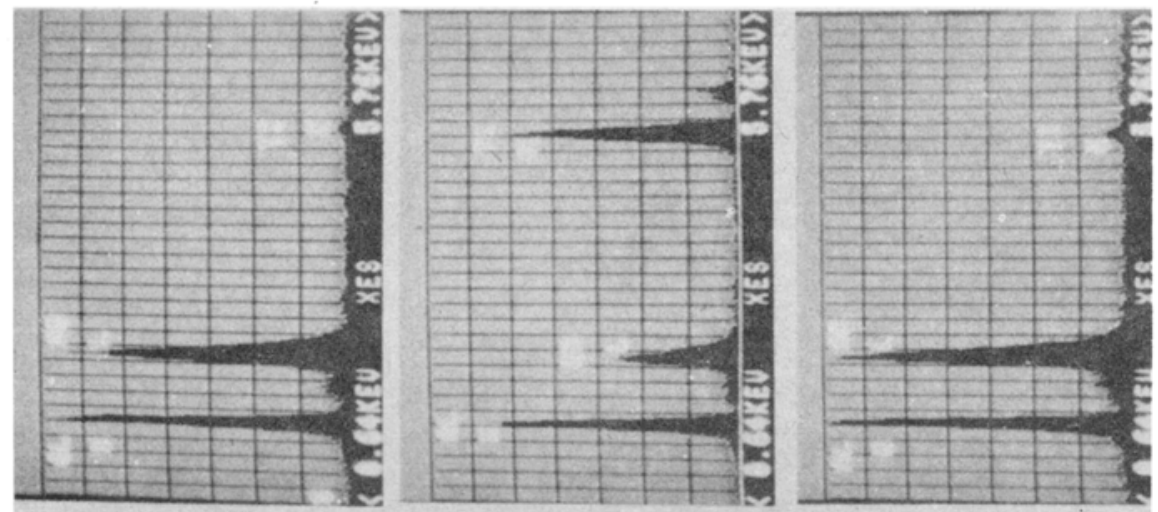

$\stackrel{\stackrel{o g}{\Xi}}{\Xi}$

ซ్

递

商

案

采

3

造

동]

응

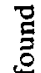

品

要

흘

总

$\frac{1}{0}=$

苋

.

苍

总

잉

悹.

胥

马

造
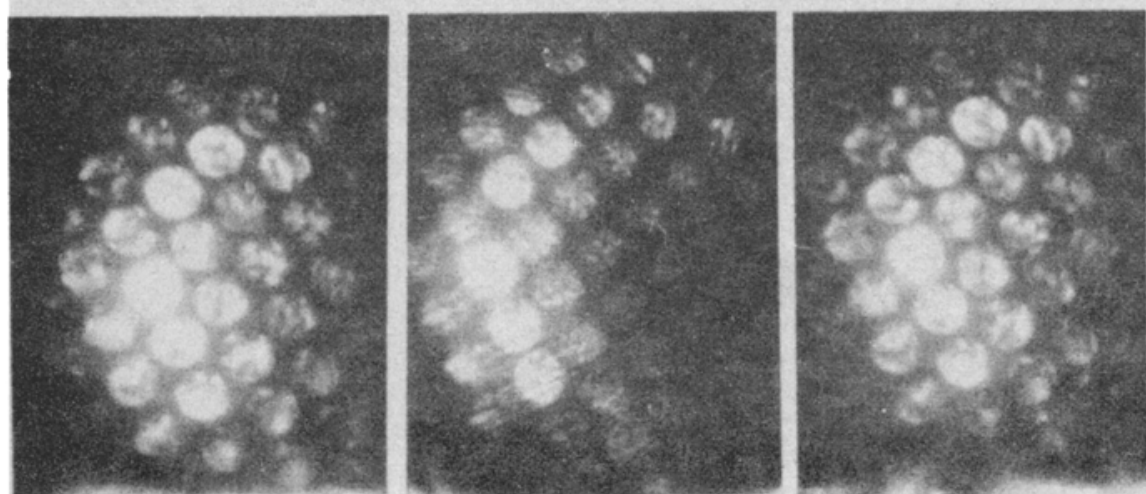

항

踏

을

행

递

E

施

a

.

总承 

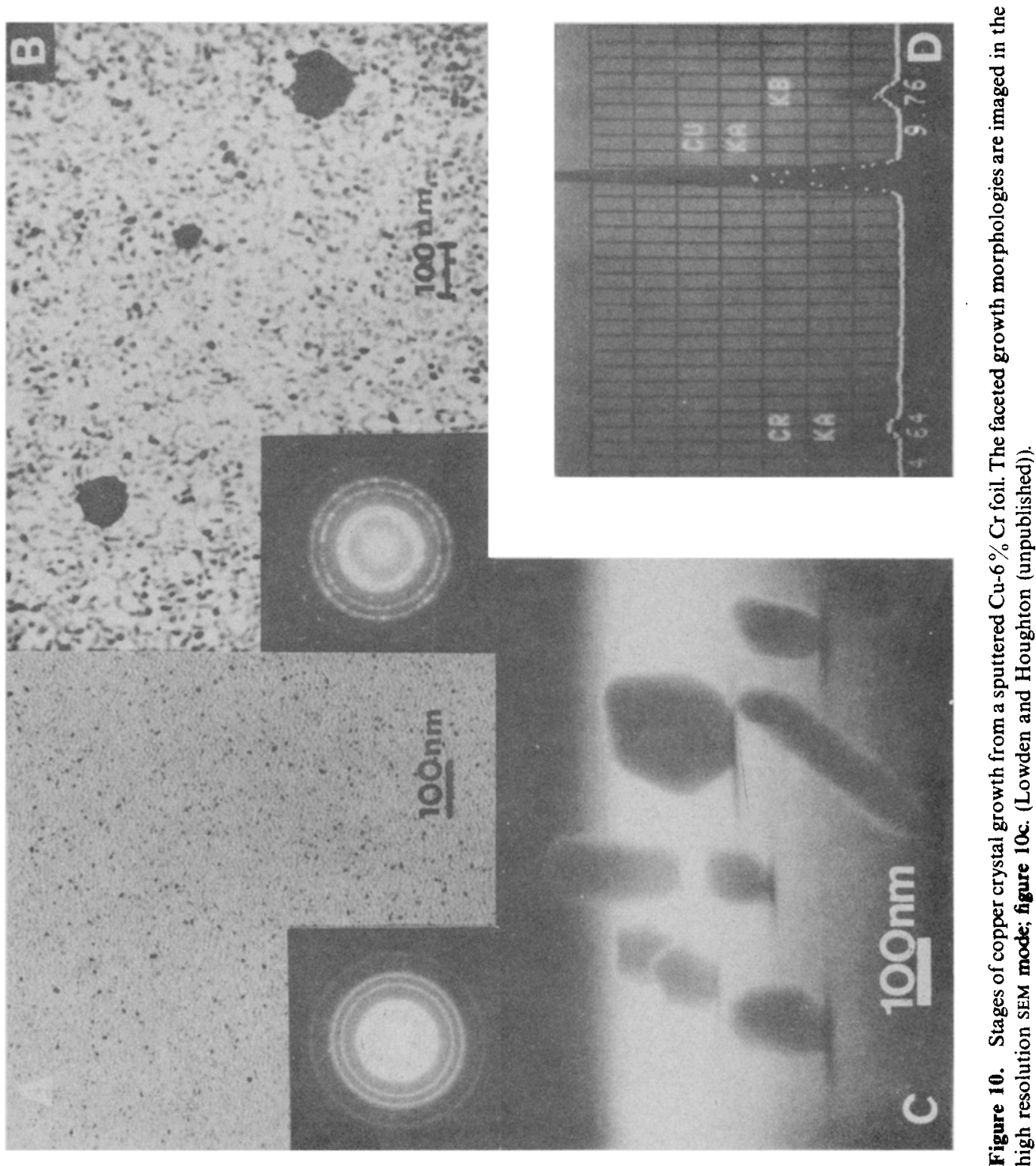
prospect of obtaining simultaneous microstructural and microchemical data on an unprecedented scale. It is equally clear that problems in specimen preparation generally exist and must be overcome by careful experimental design if the full potential of the instrument is to be realized as an aid in the study of engineering materials.

Studies currently underway at the McMaster-Toronto facility aim to exploit this potential for such diverse materials as crystalline ceramics, glasses, polymers, metallurgical coke, non-metallic inclusions and minerals, as well as a wide variety of metallic systems of interest to physical metallurgists. The unparalleled combination of analysis techniques and imaging modes offered by the STEM allows access to a new level of experimental information, and it is expected that this, in turn, will stimulate a new generation of thought in the science of materials.

\section{Acknowledgements}

The author is indebted to his colleagues at McMaster and Toronto for many stimulating discussions. Two senior research associates directly associated with the STEM, Dr Brian Robertson and Dr Derek Houghton, have contributed much to its development and application. The research was supported by grants from Energy, Mines and Resources, Canada and The Natural Sciences and Engineering Research Council, Canada.

\section{References}

Brown R, Badekas H and Purdy G R (to be published)

Gilmour J B, Purdy G R and Kirkaldy J S 1972 Met. Trans. 3 1455, 3213

Goldstein J 1979 Introduction to analytical electron microscopy (ed) J J Hren et al (New York: Plenum Press) 83

Hillert M 1960 Paraequilibrium Internal Report of the Swedish Institute for Metals Research

Houghton D C, Weatherly G C and Embury J D (to be published)

Lowden P and Houghton D C (unpublished)

Narita K 1975 Trans. I.S.I.J. 15147

Perovic V, Purdy G R and Weatherly G C 1984 (research in progress)

Solorzano-Naranjo I G and Purdy G R (unpublished)

Speich G R, Demarest V A and Miller R L 1981 Met. Trans. 12A 1419

Wycliffe P A, Purdy G R and Embury J D 1981 Fundamentals of dual phase steels (ed) R A Kot and B L Bramfitt (AIME) 59

Wycliffe P A 1981 Ph.D. Thesis, McMaster University, Hamilton, Canada 